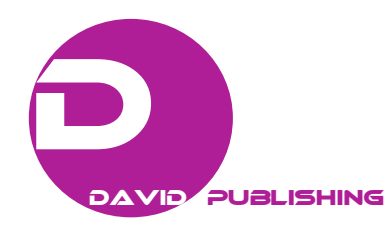

\title{
Improvement of Technological Solutions for Sheet Piling Walls Made of U-Shape Piles
}

\author{
Victor Petrosyan and Michael Doubrovsky \\ Sea, River Ports and Waterways Department, Odessa National Maritime University, Odessa 65029, Ukraine
}

\begin{abstract}
As it is evident from the practice of construction and maintenance of thin retaining walls, the degree of developing of frictional forces in interlock connections of steel sheet U-shape piles essentially influences the realization of the values of geometric characteristics of the piles cross-section (the moment of inertia and the section modulus) reduced to the length unit of the construction. The article offers new and simple solutions for realization and economically effective technological approaches to provide joint work of the sheet piles being considered, which improve the adequacy of design and reliability of maintenance of thin retaining walls.
\end{abstract}

Key words: Sheet piling walls, steel U-shape piles, interlock connections.

\section{Introduction}

A possibility of mutual displacements of adjacent steel U-shape piles in their interlock connections at the stage of the maintenance as the result of friction resistance deficit in the interlocks [1-4] is a drawback of traditional constructions of thin retaining walls. This can happen, for example, in case the wall bends under the perception of backfill soil active pressure (particularly, in the zone of maximal horizontal deflection of the wall).

Thus, due to the location of the U-shape sheet piles interlock connections on the neutral axis of the wall (or close to it), the actual values of major geometrical characteristics of the wall cross section, which influence the parameters of flexural rigidity of the construction, i.e., the moment of inertia and the section modulus, can be significantly lower. In some cases, this difference reaches 2-3 times against the corresponding values specified in the sheet piles manufacturers' catalogues. Such circumstance may decrease the reliability of the construction [1-3].

The values of geometric characteristics of the sheet

Corresponding author: Michael Doubrovsky, professor; research fields: maritime and port construction. E-mail: doubr@tm.odessa.ua. pile wall, as specified in the catalogues of the sheet piles manufacturers and used by project designers and contractors, are defined using assumption of fixed sheet piles in their interlock connections in longitudinal direction. These values disregard possible mutual displacements of the piles in the interlocks. The above-mentioned constructions (for example, the front wall and the anchor wall of the berthing structure made of U-shape steel sheet piles) are shown in Figs. 1 and 2.

With the purpose of avoiding the above situation, the companies - manufacturers of steel rolled sheet piles, recommend using several approaches.

At the stage of manufacturing in factory conditions, the sheet piles can be combined into packages, 2-3 single sheet piles in each, connected by pressing or welding in the interlock connections (Fig. 3).

At the stage of performing works for construction or reconstruction (repair, strengthening, etc.) of sheet pile walls, it is recommended to weld the interlocks of adjacent piles. This approach as applied to berthing structures results in significant difficulties when performing welding jobs, making them time-consuming and expensive (specifically in underwater conditions or in the zones of variable elevation of water). 


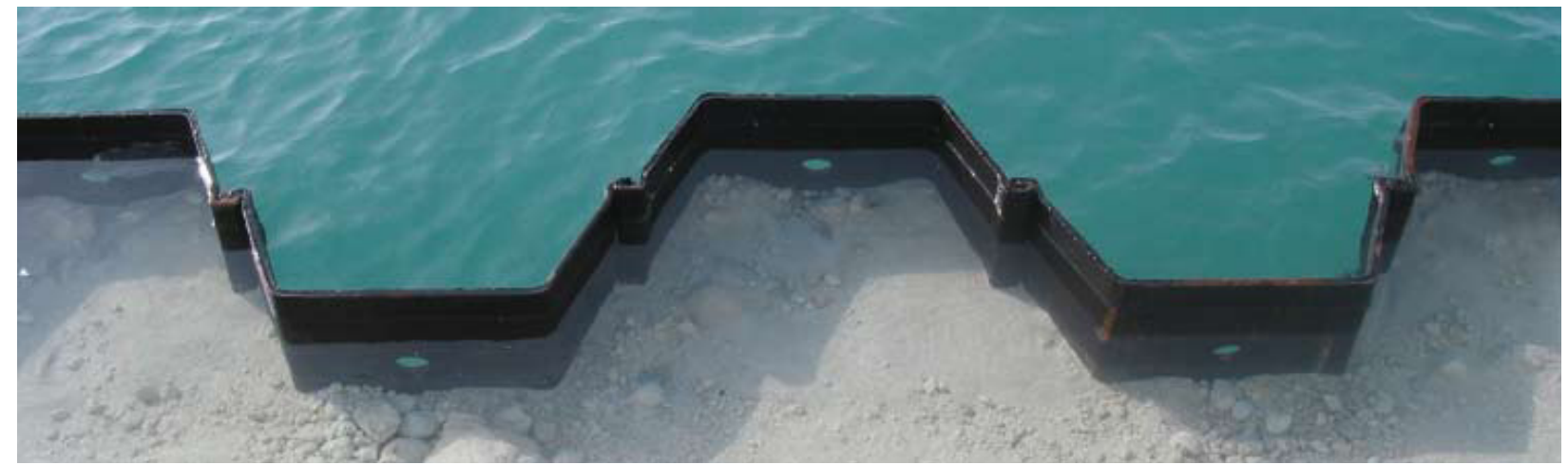

Fig. 1 Berth front wall of a steel U-shape sheet piles.

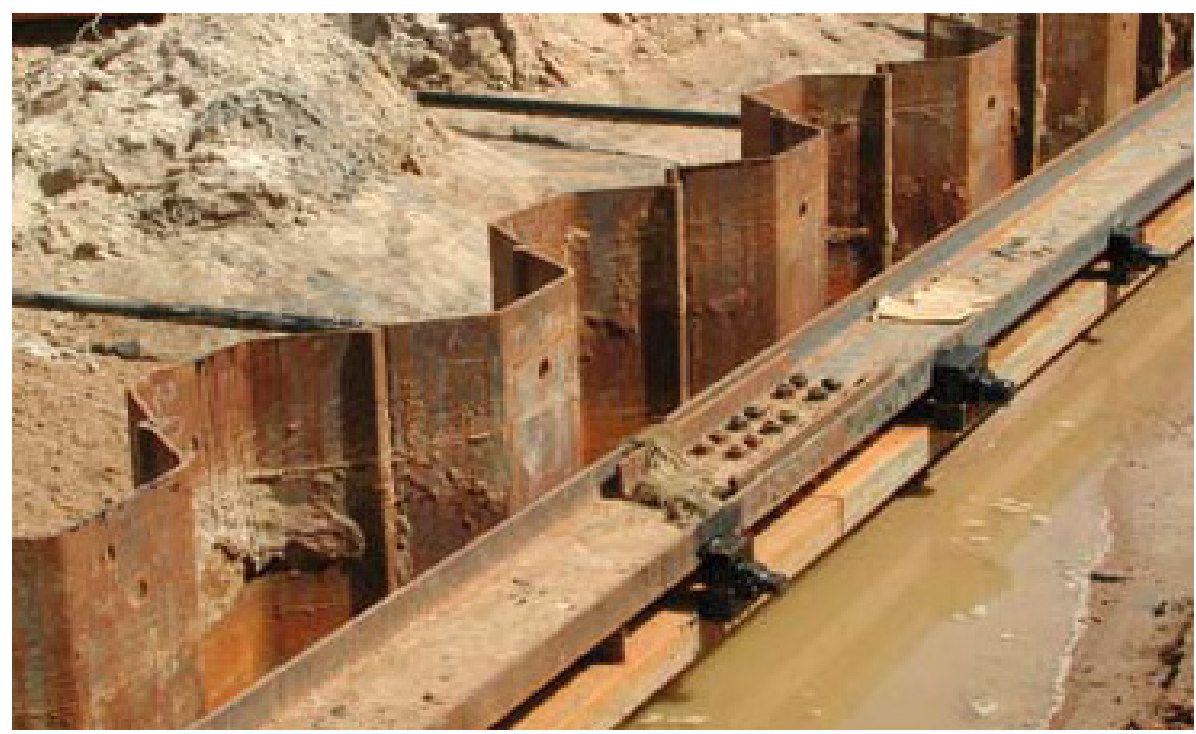

Fig. 2 Anchor wall of a steel U-shape sheet piles.

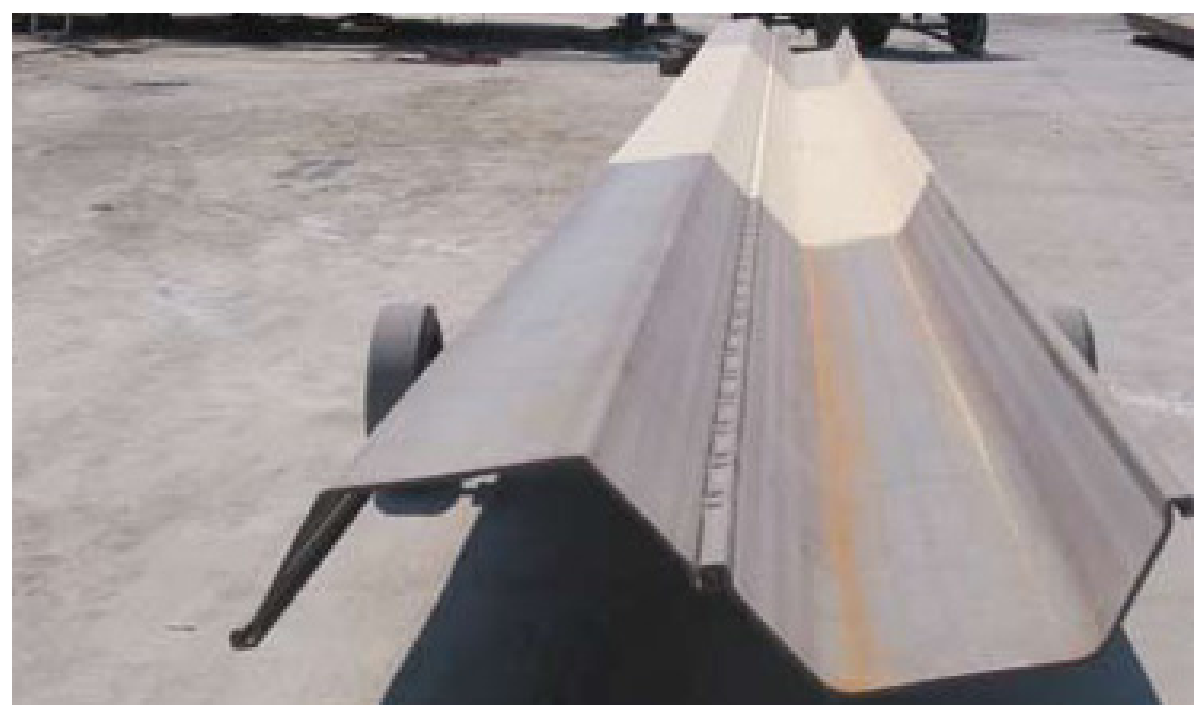

Fig. 3 Package of two U-shape sheet piles connected in the interlocks by pressing in factory conditions. 
In connection with the above, some improved engineering and technological solutions are presented in this article. They are aimed at the creation of reliable and efficient construction of sheet pile wall made of U-shape steel sheet piles with interlock connections located at the zone of the neutral axis of the wall.

\section{The Use of Construction Elements Improving Joint Work of U-Shape Sheet Piles}

In conformity with the suggested solution, the retaining wall is provided on the inside and outside with tiers of rigid straps distributed in longitudinal and vertical directions, which connect flanges of two or more piles. In this case, the straps connect only those piles that are located on the one side of the neutral axis of the construction, while the positions of the strip tiers height wise correspond to the zones of sheet piles maximum deflections.

The role of the straps consists in the prevention of mutual longitudinal displacement of adjacent piles. In such a case, the possibility of sheet piles slipping in interlock connections (irrespectively to the force of

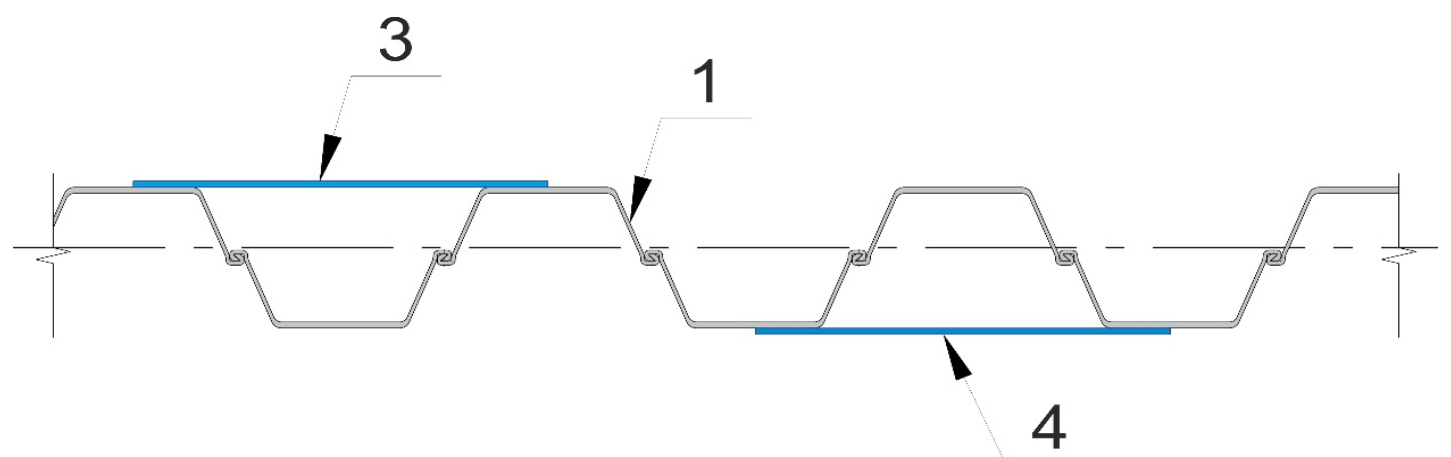

Fig. 4 Plan of the sheet pile wall.

a)

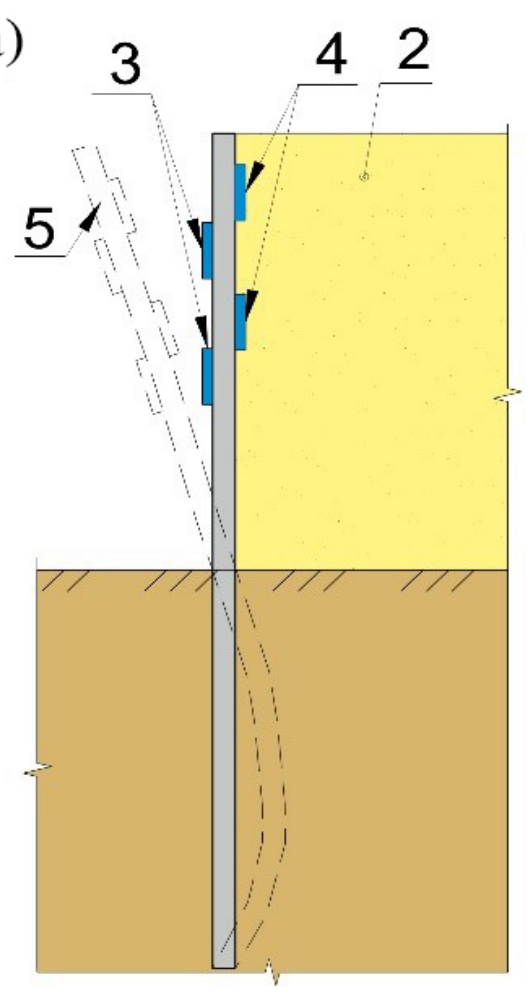

b)

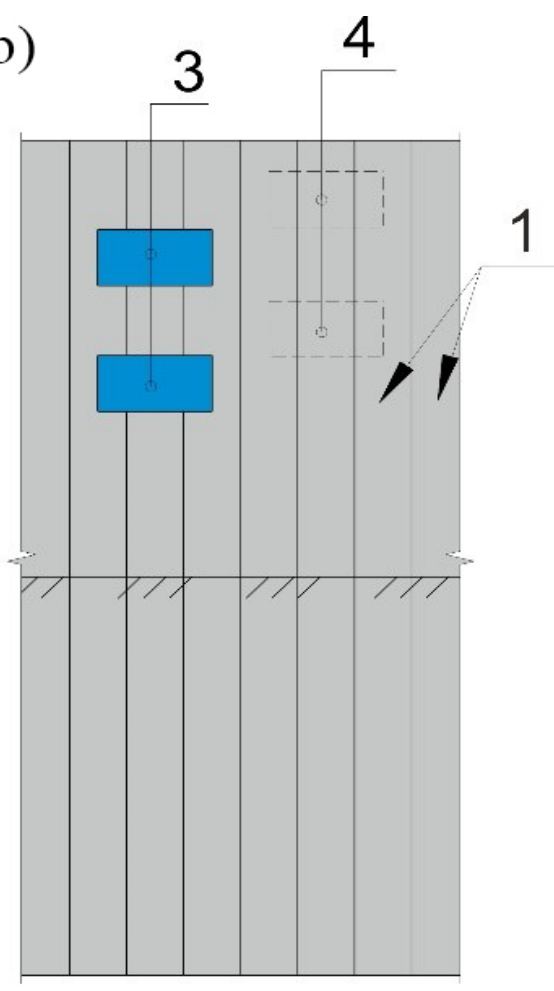

Fig. 5 Application of the rigid strips for the bulkhead: (a) cross-section; (b) and fragment of the sheet pile wall face. 
friction in the connection) is excluded. Due to this approach, a rigid connection of sheet piles is ensured, which improves the efficiency and reliability of the construction in service (calculated and real values of both moment of inertia and section modulus are the same).

Fig. 4 shows the horizontal cross-section of the berthing structure construction at the level of one of the tiers of rigid straps; Fig. 5 shows the vertical cross-section and a fragment of the construction facade.

The sheet pile retaining wall (Figs. 4 and 5) includes steel U-shape sheet piles 1, driven in soil by the "interlock" method (the locks of sheet piles are located on the neutral axis of the wall) with backfill material 2 behind. Rigid straps (for example, of steel sheet) 3 and 4 are welded to the pile flanges on both sides in the form of tiers along the whole construction. Possible deformations of the construction under the influence of the backfill soil active pressure are shown in dotted lines and defined as position 5 (Fig. 5a).

The construction of steel sheet piles 1 being considered works as follows: under the influence of the backfill soil active pressure the front wall bends as a cantilevered beam driven in the soil at the lower end; as the result of the effect of the backfill active pressure 2, wall 1 will bend and its elastic axis will take position 5. At that, due to the rigidity of the straps, the adjacent piles will not slide in relation to each other in interlocking connections, ensuring thereby maximal (in conformity to manufacturers' catalogues) values of characteristics of rigidity and geometry of cross sections of the berthing structure.

By varying the sizes of the straps and, consequently, the total length of the welding seam that fixes the plates by their perimeters to the piles flanges, and thus ensuring the connection of the mutual piles, it becomes possible to regulate the degree of free movement of the piles relative sliding in the interlock connections up to its complete elimination. In this way, the effectiveness of the straps welded to the sheet piles flanges can be essentially higher than that of the lap weld, which is made directly in the interlock connection of adjacent piles (because the length of the lap weld is limited by the corresponding length of the interlock connection of the mutual piles). For example, in the piles of European production of the type PU, the length of the lap weld around the perimeter of one strap according to the solution suggested can be 3-4 times as longer than the length of the lap weld in interlock connection at the level of the strap.

\section{Improvement of Technological Solutions for U-Shape Sheet Pile Walls}

In conformity with the solution suggested, the sheet piles in vertical plane intersect the neutral axis of the wall and the interlock connections of the piles are installed with a rake relative to the vertical. This allows ensuring a growth of friction force in the piles interlocks, which prevents mutual displacement of sheet piles in the connections and increases the degree of the construction work as a continuous structure, as well as its rigidity, reliability and effectiveness.

The solution of the task is ensured by the fact that each next pile of the sheet pile wall is placed over the interlock connection with the previous pile. Such positioning of the sheet piles in the berth wall allows transferring a part of the weight of the overlying pile to its interlock connection with the lower pile and thus increasing the friction force in the interlock, which prevents mutual displacement of the sheet piles in the interlocks.

Fig. 6 shows a plan of the sheet pile wall construction; Fig. 7-longitudinal cross-section of the construction; Fig. 8-the scheme of the effect of the overlying sheet pile on its interlock connection with the underlying pile.

The construction (Figs. 6 and 7) includes steel sheet piles 1 , which are located in the foundation soil with piles interlock connections 2 located on the neutral axis 3 , the piles being positioned with a tilt relative to the vertical.

The effective force of overlying pile on the interlock 


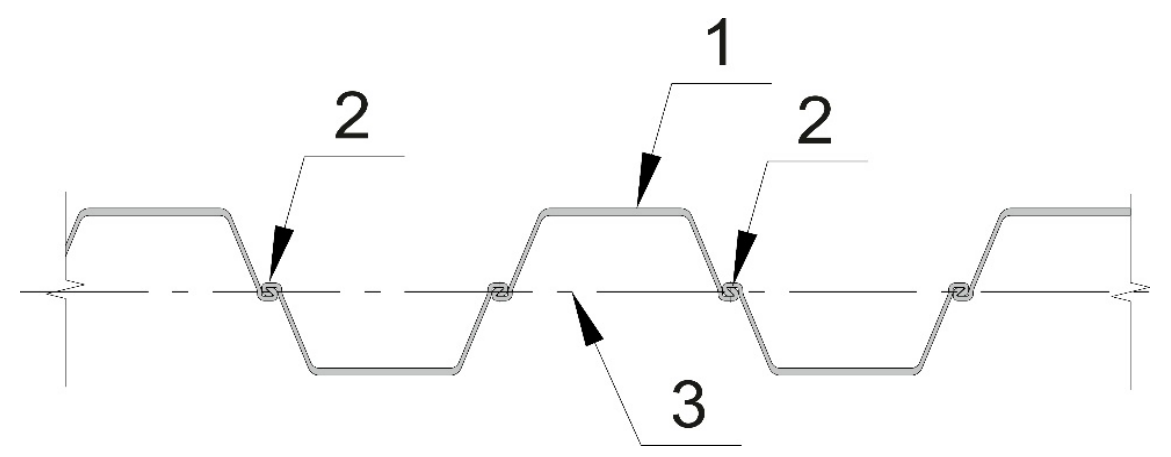

Fig. 6 Fragment of the sheet pile wall.

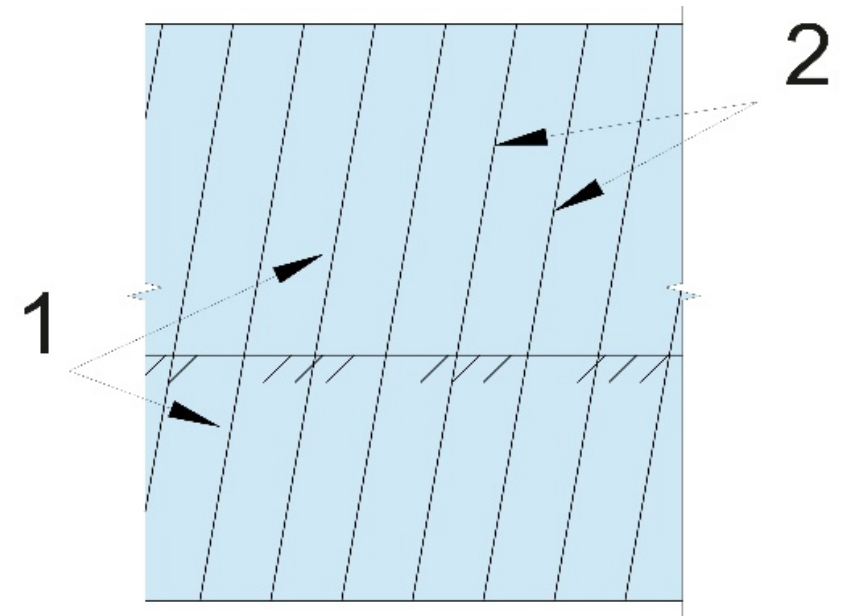

Fig. 7 Fragment of longitudinal cross-section of the sheet pile wall.

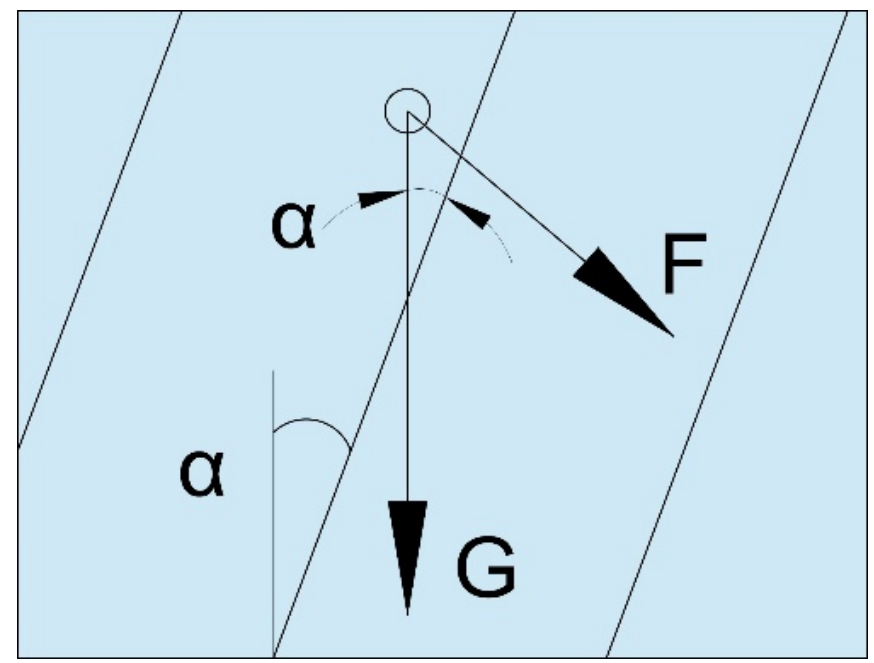

Fig. 8 Scheme of the effect of overlying pile on the interlock connection with the underlying pile.

connection with the underlying one is determined by the formula according to Fig. 8:

$$
F=G \cdot \sin \alpha
$$

where:

$G$ - the resultant gravity of the overlying pile; $\alpha$-angle of the piles tilt to the vertical.

The force $F$, normal to the axis of the interlock connection, increases the frictional force, which appears at relative displacement of adjacent piles in the interlock connection and prevents sliding of one pile 
relative to the other in the interlock connection. Corresponding friction force increment in the interlock connection $\Delta_{f}$, stipulated by the effect of the force $F$, will be equal to:

$$
\Delta_{f}=F \cdot k_{t}
$$

where, $k_{t}$-co-efficient of friction in the interlock connection of the sheet piles, to be determined experimentally for concrete soils, in which the sheet pile wall is being built and maintained $[5,6]$.

From the point of view of quantitative evaluation of the influence of the force $F$ on the friction force increment in the interlock connection of sheet piles, the following is worth marking. Theoretically, maximal value of this force with fixed weight of sheet pile $G$ according to Eq. (1) corresponds to angle $\alpha=$ $90^{\circ}$, i.e., to horizontal position of the sheet piles. Obviously, such position of sheet piles certainly disagrees with the constructive idea of the considered berthing structure (sheet piling wall).

Technical parameters of the equipment and mechanisms for driving of sheet piles during construction, reconstruction, repair or strengthening the structures being considered present a real limitation of angle $\alpha$. The question is, for example, of drop hammer (diesel, hydraulic), pressing mechanisms (static, hydraulic) or vibro-hammers (electric, hydraulic), which can be either fixed to the heads of the piles being driven, or move on guide mast. In the last case, the angle of rake of the ram guides can make $4-5^{\circ}$ to both sides.

At the value of resultant gravity of the overlying pile of standard (for European production) type $G=$ $30 \mathrm{kN}$ and the coefficient of friction $k_{t}=0.65$, the use of Eqs. (1) and (2) allows determining friction force increment in the interlock connection of adjacent piles as $\Delta_{f}=2.67 \mathrm{kN}$.

\section{Conclusions}

The engineering and technological solutions presented in this article have been elaborated based on quite simple and non-expensive approaches, namely:
- The provision of pairs or groups of piles having the same orientation relative to the neutral axis of the sheet pile wall with the uniting rigid straps;

- The provision for the tilt of sheet piles relative to the vertical in the longitudinal direction of the berthing structure.

The solutions offered ensure:

- more reliable integrity of adjacent sheet piles in the construction of a berthing structure;

- approach of actual values of sheet piling walls geometrical characteristics (inertia moment, section modulus) to their values in the catalogues offered by the manufacturers of steel rolled sheet piles;

- improvement of quality and effectiveness of design solutions;

- lowering the expenses for the maintenance of retaining sheet pile walls.

\section{References}

[1] Doubrovsky, M. P., Petrosyan, V. N., and Meshcheryakov, G. N. 2010. "Investigation of the Specificity of Interaction of Steel Sheet Piles with Soil during Operation and Maintenance, Reconstruction and Repair of Water Transport Constructions." Bulletin of Odessa State Marine University 29: 69-80.

[2] Doubrovsky, M. P., Poizner, M. B., and Petrosyan. V. 2001. "Modern Technologies for Port Quay Structures' Reconstruction." In Proc. of the 5th International Seminar on Renovation and Improvements to Existing Quay Structures, Technical University of Gdansk, Gdansk, Poland, Volume 1, 127-34.

[3] Doubrovsky, M. P., Meshcheryakov, G. N., Petrosyan, V. N., and Dubrovska, O. M. 2011. "Full-Scale Physical Modelling of the System 'Granular Media-Steel Sheet Piling"”. In Advances in Applied Physics \& Material Science Congress APMAS 2011. Book of abstracts. Vol. 1. Antalya, Turkey, 350.

[4] Doubrovsky, M. P., and Poizner, M. B. 2016. Innovative Development of Coastal, Port and Marine Engineering. Saarbrucken, Germany: Lambert Academic Publishing.

[5] Doubrovsky, M. P., Petrosyan, V. N., and Meshcheryakov, G. N. 2011. "Field Experimental Researches of Sheet Piles Pressing/Building structures." Interdepartmental Scientific and Technical Collected Book "Soil Mechanics and Building of Foundations", Issue 75, Book 2, 338-44.

[6] Doubrovsky, M. P., Meshcheryakov, G. N., and 
Petrosyan, V. N. 2011. "Large Scale Laboratory Tests of Sheet Piles Interlock Connections Interaction with Soil
Media." Soil Mechanics and Foundation Engineering, Issue 75, Book 2, 113-9. 